\title{
Diet but not aerobic exercise training reduces skeletal muscle TNF- $\alpha$ in overweight humans
}

\author{
K. E. Ferrier ${ }^{1}$ P. Nestel $^{1}$ - A. Taylor ${ }^{1}$ B. G. Drew ${ }^{1}$ B. A. Kingwell ${ }^{1}$ \\ ${ }^{1}$ Alfred and Baker Medical Unit, Baker Medical Research Institute, Melbourne, Victoria, Australia
}

\section{Abstract}

Aims/hypothesis. Our aim was to test the hypothesis that TNF- $\alpha$ protein levels in skeletal muscle are important in mediating the improvements in glucose homeostasis that are associated with diet and exercise regimens intended to reduce cardiovascular risk.

Methods. We recruited 20 people with a body mass index of $32.1 \pm 1.2 \mathrm{~kg} / \mathrm{m}^{2}$ (mean \pm SEM) and one other component of the metabolic syndrome. The average age was $51.2 \pm 8.1$ years (mean $\pm \mathrm{SD}$ ). Of the $20 \mathrm{sub}$ jects, 6 were men and 14 were women. All subjects completed an 8-week control period, followed by randomisation to 8 weeks of moderate cycling exercise (30 min, three times per week) or to a diet with the following characteristics: low in saturated fat, high in fibre, low glycaemic index, rich in complex carbohydrates.

Results. Diet induced a small reduction in body mass index $(3.0 \pm 0.7 \%, p<0.05)$, although weight loss was not intended. Exercise training increased maximum oxygen consumption by $12 \pm 6 \%(p<0.05)$. Both interventions reduced fasting plasma insulin levels by about $20 \%$. Diet reduced skeletal muscle TNF- $\alpha$ protein by $54 \pm 10 \%(p<0.05)$, an effect that was independent ( $p=0.94$ in covariate analysis) of the small concurrent weight loss $(-2.8 \pm 0.7 \mathrm{~kg})$. Levels of GLUT4 protein were unchanged in the diet group. In contrast, exercise training did not significantly change TNF- $\alpha$ protein expression, but GLUT4 protein expression increased by $105 \pm 37 \%(p<0.05)$.

Conclusions/interpretation. These data indicate that the metabolic benefits of a diet aimed at cardiovascular risk reduction are associated with a decrease in skeletal muscle TNF- $\alpha$ protein.

Keywords Aerobic exercise - Diet - Glucose . GLUT4 - Glycaemic index · Metabolic syndrome · TNF- $\alpha \cdot$ Type 2 diabetes
Received: 3 October 2003 / Accepted: 26 January 2004 Published online: 26 March 2004

(C) Springer-Verlag 2004

B. A. Kingwell (®)

Alfred and Baker Medical Unit, Baker Medical Research Institute, P.O. Box 6492, St Kilda Road Central, Melbourne, Victoria, 8008 Australia

E-mail: b.kingwell@alfred.org.au

Tel.: +61-3-92763261, Fax: +61-3-92762495

Abbreviations: HOMA, homeostasis model assessment . $\mathrm{VO}_{2}$ max, maximum oxygen consumption

\section{Introduction}

The cytokine TNF- $\alpha$ has been implicated as a critical mediator of insulin resistance, particularly in relation to obesity $[1,2]$. It affects insulin resistance via two major mechanisms, inhibition of insulin receptor signalling [3] and down-regulation of the GLUT4 glucose transporter [4]. This was thought to occur via the actions of adipose-derived TNF- $\alpha$, through autocrine mechanisms in adipose tissue and paracrine effects on skeletal muscle [5]. Indeed, TNF- $\alpha$ levels are higher in the adipose tissue of obese and insulin-resistant rodents and humans than in healthy animals or individuals $[1,2,5,6]$. More recently it has been shown that TNF- $\alpha$ is also expressed in skeletal muscle and that 
levels are four-fold higher in insulin-resistant, obese humans than in healthy humans [7]. Thus TNF- $\alpha$ appears to have direct autocrine actions within skeletal muscle. These actions are probably significant given that skeletal muscle is the major site of glucose disposal in the body.

Weight loss and exercise therapy are well known for their efficacy in the treatment of insulin resistance. It is possible that some of these effects are mediated through a reduction in TNF- $\alpha$, either in adipose tissue or in skeletal muscle. Energy restriction resulting in weight loss has been shown to reduce TNF- $\alpha$ mRNA and protein levels in adipose tissue $[5,6]$. Skeletal muscle, however, is less well studied. Recently it was shown that massive weight loss through malabsorptive surgery can reduce TNF- $\alpha$ mRNA levels in skeletal muscle [8]. In the same study, the more moderate weight loss associated with energy restriction had no effect. The effects of TNF- $\alpha$ on dietary modification, undertaken with a view to reducing cardiovascular risk factors rather than weight, have not been studied to date.

Strenuous exercise elicits an inflammatory response that includes increases in TNF- $\alpha$ in plasma [9, 10]. However, the effects of chronic moderate aerobic exercise training on plasma TNF- $\alpha$ levels in humans are unclear, with some studies showing increases [11] and others decreases [12]. In rats, TNF- $\alpha$ mRNA and protein levels in adipose tissue are increased by moderate aerobic training [13]. In contrast, resistance training reduced TNF- $\alpha$ skeletal muscle mRNA and protein in frail elderly humans [14]. No previous studies have examined the effects of moderate aerobic training regimens, which are known to improve conventional cardiovascular risk factors including blood pressure and insulin resistance $[15,16]$, on skeletal muscle TNF- $\alpha$ protein levels in humans.

Using a randomised, parallel, longitudinal design, this study therefore examined the effects of a specific diet or moderate aerobic exercise, each done for 8 weeks, on skeletal muscle TNF- $\alpha$ and GLUT4 protein levels. Characteristics of the diet used were: low in saturated fat, high in fibre, high in complex carbohydrates, low glycaemic index, no intended weight loss. The aim was to determine whether a reduction in skeletal muscle TNF- $\alpha$ is associated with diet- and exercise-induced improvements in glucose homeostasis, and whether such effects are related to an increase in skeletal muscle GLUT4 protein levels.

\section{Subjects and methods}

Subjects. All participants gave informed consent for participation in the study, which was undertaken with the approval of The Alfred Healthcare Group Ethics Committee and performed in accordance with the Declaration of Helsinki of the World Medical Association. We recruited 20 participants through a newspaper advertisement. The group baseline characteristics
Table 1. Baseline characteristics of the diet and exercise groups

\begin{tabular}{lcc}
\hline Characteristic & $\begin{array}{l}\text { Diet } \\
\text { group }\end{array}$ & $\begin{array}{l}\text { Exercise } \\
\text { group }\end{array}$ \\
\hline Sex (female/male) & $7 / 3$ & $7 / 3$ \\
BMI (kg/m ${ }^{2}$ ) & $33 \pm 2$ & $31 \pm 2$ \\
Weight (kg) & $95 \pm 4$ & $89 \pm 4$ \\
Waist-to-hip ratio & $0.88 \pm 0.02$ & $0.88 \pm 0.03$ \\
Supine systolic blood pressure & $130 \pm 4$ & $123 \pm 3$ \\
$\quad$ (mm Hg) & & \\
Supine diastolic blood pressure & $71 \pm 2$ & $71 \pm 3$ \\
$\quad$ (mm Hg) & & \\
Total cholesterol (mmol/l) & $5.37 \pm 0.35$ & $5.61 \pm 0.20$ \\
LDL cholesterol (mmol/l) & $3.24 \pm 0.28$ & $3.55 \pm 0.19$ \\
HDL cholesterol (mmol/l) & $1.09 \pm 0.07$ & $1.16 \pm 0.07$ \\
Triglycerides (mmol/l) & $1.53 \pm 0.21$ & $1.42 \pm 0.27$ \\
Fasting plasma glucose (mmol/l) & $5.63 \pm 0.26$ & $5.43 \pm 0.14$ \\
Diabetic/pre-diabetic (number) [35] & $1 / 0$ & $0 / 1$ \\
VO ${ }_{2}$ max (ml-kg-1.min ${ }^{-1}$ ) & $21.6 \pm 2.9$ & $21.2 \pm 2.6$ \\
\hline
\end{tabular}

The average age and age range (all participants) were: $51.2 \pm 8.1$ years $($ mean $\pm \mathrm{SD}$ ) and 33 to 59 years respectively

(Table 1) included: sex: 6 men, 14 women; age: $51.2 \pm 8.1$ years (mean $\pm \mathrm{SD}$ ); age range: 33 to 59 years. All participants met the following inclusion criteria: aged 30 to 60 years; BMI $26 \mathrm{~kg} / \mathrm{m}^{2}$ or more; waist circumference above $95 \mathrm{~cm}$ (men) and above $85 \mathrm{~cm}$ (women). They also all had at least one other unequivocal characteristic of the metabolic syndrome including: HDL cholesterol less than $1 \mathrm{mmol} / \mathrm{l}$; triglycerides above $2 \mathrm{mmol} / \mathrm{l}$; blood pressure higher than 140/90 mm Hg; fasting plasma insulin above $15 \mathrm{mU} / \mathrm{l}$; and fasting plasma glucose $6.1 \mathrm{mmol} / \mathrm{l}$ or more and/or 2-h post-glucose load $7.8 \mathrm{mmol} / \mathrm{l}$ or more. Whereas some of these components are based on criteria of the European Group for the study of Insulin Resistance [17], we raised the thresholds slightly for others. We did not characterise the subjects as suffering from the metabolic syndrome. Candidates were excluded, if they were taking hormone replacement therapy, hypoglycaemic, cholesterol-lowering, antihypertensive or other vasoactive medication. We also excluded candidates who smoked, consumed excessive alcohol ( $>4$ standard drinks per day for men, $>2$ for women), had coronary artery disease (on examination of their history or screening) or any other major illness or were involved in an exercise programme.

Study design. The study was of a randomised, parallel, longitudinal design. After screening, all participants initially completed an 8-week control period, in which they were instructed to continue with their normal dietary and exercise habits. This control period was needed to control for the potential effects of measurement familiarisation. It was followed by randomisation either to an 8-week dietary or 8-week exercise intervention. Both interventions were completed by ten participants (three men and seven women for each intervention).

Study protocol. Measurements were performed at baseline, after the control period, and again after the intervention period. Anthropometric measures included BMI and waist-to-hip ratio. A fasting blood sample was taken for analysis of glucose and insulin levels. After the control period, and again following the intervention period, we did a vastus lateralis muscle biopsy for analysis of skeletal muscle TNF- $\alpha$ and GLUT4 protein levels. Compliance with the exercise programme was assessed by 
Table 2. Composition of the prescribed diet

\begin{tabular}{lcl}
\hline Dietary component & Amount & Characteristic \\
\hline Carbohydrate & $55 \%$ energy & Complex, low glycaemic \\
Fat & $30 \%$ energy & Low saturates, raised n-3, raised mono- and polyunsaturates \\
Protein & $15 \%$ energy & Predominantly of plant origin \\
Fibre & $>30$ g per day & Soluble and insoluble \\
Sodium & $<100$ mmol per day & \\
\hline
\end{tabular}

maximum oxygen consumption $\left(\mathrm{VO}_{2} \mathrm{max}\right)$ during an incremental bicycle exercise test. Dietary compliance was assessed using a 4-day food record, in which food and drink consumed during that time were weighed.

Dietary modification. Prior to the baseline period, the usual food pattern of each subject was assessed with food questionnaires and records of weighed food using a computer program designed by the Anti-Cancer Council, Melbourne, Australia. Participants randomised to the diet intervention had access to a plan developed by a dietician. This plan allowed these participants to modify their diets to approximate that prescribed (Table 2). The main objectives were: reduction of saturated fats, and the partial substitution of mono and disaccharides by starchy complex carbohydrates. Before commencing the intervention, these participants received counselling on how to meet these requirements. They were also given a document detailing recommended and not-recommended foods, plus an example of a daily menu. The primary goal was risk factor reduction other than weight loss (hence the recommended level of fat intake). Weight loss was not discouraged, and given the change in macronutrient composition, was anticipated. Participants were contacted weekly by phone while undertaking the dietary changes.

Exercise training. Participants randomised to the exercise intervention were provided with a Repco Compucycle No. RC500 exercise bicycle (AS-4092, Taiwan) for use at their home during the intervention period. Participants rode the bicycle three times per week at an intensity of $65 \%$ of their predetermined maximum heart rate, which was calculated as follows: $0.65 \times$ (maximum heart rate - resting heart rate $)+$ resting heart rate. Heart rate monitors (Polar Protrainer, Polar Electro Oy, Kempele, Finland) were provided to monitor intensity. The exercise sessions lasted 40 minutes, including a 5-minute warm-up and cool-down session.

Maximum oxygen consumption. We measured $\mathrm{VO}_{2}$ max using a graded exercise test on an electrically braked cycle ergometer (Ergoline 900, Bitz, Germany). The workload increased at a rate of $20 \mathrm{~W}$ per minute. Oxygen and carbon dioxide were measured using a cardiopulmonary exercise system (Quark $b^{2}$, Cosmed, Rome, Italy). Heart rate was recorded telemetrically during the exercise test. The achievement of $\mathrm{VO}_{2}$ max was established by a plateau in oxygen consumption, a respiratory exchange ratio above 1.1, a heart rate at maximum level for age (i.e. 220 - age) or fatigue and failure to maintain the workload despite encouragement. $\mathrm{VO}_{2} \max$ was regarded as the average oxygen consumption over the last 30 seconds of exercise.

All participants were screened for coronary disease and other abnormalities using a 12-lead electrocardiograph before and during exercise (Cardiovis plus, Cosmed, Rome, Italy). A normal electrocardiograph recording throughout the baseline exercise test was a prerequisite for further progression in the study.
Glucose and insulin. At screening, glucose metabolism was assessed using an oral glucose tolerance test following an overnight fast. Venous blood samples $(10 \mathrm{ml})$ were drawn into lithium heparin tubes before, and at 30-min intervals after consumption of a 75-g oral glucose load (glucose monohydrate dissolved in $200 \mathrm{ml}$ flavoured water; Glucotol, Orion Laboratories, Welshpool, Australia). Fasting samples were also collected after the control and intervention periods. All blood was centrifuged at $3000 \mathrm{rev} / \mathrm{min}$ and $4{ }^{\circ} \mathrm{C}$ for 15 minutes, and plasma was stored immediately at $-20{ }^{\circ} \mathrm{C}$. Plasma glucose levels were determined enzymatically using a Gluco-quant glucose assay kit (Roche Diagnostics, Mannheim, Germany) and a Cobas-Fara centrifugal analyser (Roche Diagnostic Systems, Basel, Switzerland). Insulin was analysed using a humaninsulin-specific radioimmunoassay kit (Linco Research, St. Charles, Mo., USA). Beta cell function and insulin resistance index were calculated using the homeostasis model assessment $($ HOMA), where beta cell function $(\%)=(20 \times$ fasting insulin $[\mathrm{mU} / \mathrm{l}])$ / (fasting glucose $[\mathrm{mmol} / \mathrm{l}]-3.5)$, and insulin resistance index $=$ (fasting insulin $[\mathrm{mU} / \mathrm{l}] \times$ fasting glucose $[\mathrm{mmol} / \mathrm{l}]) / 22.5[18,19]$.

Lipids. Blood was collected into EDTA tubes and centrifuged for 15 minutes at $3000 \mathrm{rev} / \mathrm{min}$ and $4{ }^{\circ} \mathrm{C}$, and plasma was stored immediately at $-20{ }^{\circ} \mathrm{C}$. Total, LDL and HDL cholesterol, as well as triglyceride levels were determined enzymatically with a Cobas-Fara centrifugal analyser (Roche Diagnostic Systems).

Urinary sodium excretion. Participants collected all urine excreted during a 24-hour period into a bottle. Urinary sodium was analysed with a Hitachi 917 Analyzer (Roche, Mannheim, Germany), using an ion-selective electrode.

Skeletal muscle TNF- $\alpha$ protein. Levels of TNF- $\alpha$ were determined in vastus lateralis muscle biopsies by western immunoblotting. Monoclonal anti-TNF- $\alpha$ antibodies (Chemicon International, Victoria, Australia) were used in conjunction with a horseradish peroxidase conjugated anti-mouse secondary antibody (Bio-Rad, Hercules, Calif., USA). Blots were digitised and quantitated using Optimas software (version 6.5.1, MediaCybernetics, Silver Spring, Md., USA).

Skeletal muscle GLUT4 protein. Levels of GLUT4 were determined in vastus lateralis muscle biopsies by western immunoblotting. A goat polyclonal immunoglobulin $\mathrm{G}$ antibody directed against the C-20 region of the GLUT4 protein (Santa Cruz Biotechnology, Santa Cruz, Calif., USA) was used in conjunction with a donkey anti-goat immunoglobulin $\mathrm{G}$ secondary antibody, to which horseradish peroxidase was conjugated (Santa Cruz Biotechnology). Blots were digitised and quantitated using Optimas software (MediaCybernetics).

Statistics. To compare the post-control values with the baseline and post-intervention values for each group, we did Repeated Measures ANOVA. Individual means were compared using the 
Table 3. Compliance with diet and exercise regimens

\begin{tabular}{|c|c|c|c|c|}
\hline \multirow[t]{2}{*}{ Parameter } & \multicolumn{2}{|l|}{ Diet group } & \multicolumn{2}{|l|}{ Exercise group } \\
\hline & Post control & Post diet & Post control & Post exercise \\
\hline Protein (grams) & $96 \pm 6$ & $98 \pm 7$ & $95 \pm 11$ & $79 \pm 7$ \\
\hline Protein (\% energy intake) & $14.3 \pm 0.8$ & $18.1 \pm 0.9^{b}$ & $16.5 \pm 1.3$ & $14.9 \pm 0.6$ \\
\hline Total fat (grams) & $81 \pm 4$ & $44 \pm 5^{b}$ & $68 \pm 11$ & $60 \pm 5$ \\
\hline (\% of total fat) & $49 \pm 1$ & $42 \pm 2^{b}$ & $42 \pm 2$ & $37 \pm 2$ \\
\hline Mono-unsaturated fat (grams) & $27 \pm 2$ & $15 \pm 2^{b}$ & $25 \pm 5$ & $23 \pm 2$ \\
\hline (\% of total fat) & $36 \pm 1$ & $38 \pm 1$ & $40 \pm 1$ & $42 \pm 1$ \\
\hline Polyunsaturated fat (grams) & $11 \pm 1$ & $8 \pm 1^{\mathrm{a}}$ & $11 \pm 2$ & $12 \pm 2$ \\
\hline (\% of total fat) & $15 \pm 1$ & $20 \pm 2^{\mathrm{a}}$ & $18 \pm 2$ & $21 \pm 2$ \\
\hline Carbohydrates (grams) & $311 \pm 32$ & $278 \pm 32$ & $250 \pm 25$ & $241 \pm 27$ \\
\hline $\operatorname{BMI}\left(\mathrm{kg} / \mathrm{m}^{2}\right)$ & $33 \pm 2$ & $32 \pm 2^{b}$ & $31 \pm 1$ & $31 \pm 1$ \\
\hline Weight (kg) & $96 \pm 5$ & $93 \pm 5^{b}$ & $88 \pm 4$ & $87 \pm 4$ \\
\hline Waist-to-hip ratio (both sexes) & $0.895 \pm 0.021$ & $0.875 \pm 0.025^{\mathrm{a}}$ & $0.887 \pm 0.034$ & $0.872 \pm 0.027$ \\
\hline Waist-to-hip ratio (men) & $0.968 \pm 0.018$ & $0.958 \pm 0.033$ & $1.013 \pm 0.070$ & $0.986 \pm 0.031$ \\
\hline Waist-to-hip ratio (women) & $0.863 \pm 0.019$ & $0.840 \pm 0.022$ & $0.833 \pm 0.014$ & $0.823 \pm 0.012$ \\
\hline $\mathrm{VO}_{2} \max \left(\mathrm{ml} \cdot \mathrm{kg}^{-1} \cdot \mathrm{min}^{-1}\right)$ & $21.3 \pm 2.5$ & $21.5 \pm 2.7$ & $21.0 \pm 2.5$ & $23.6 \pm 3.2^{\mathrm{a}}$ \\
\hline Maximum workload (W) & $169 \pm 17$ & $171 \pm 18$ & $151 \pm 21$ & $178 \pm 22^{a}$ \\
\hline
\end{tabular}

${ }^{\mathrm{a}} p<0.05$ vs post-control value; ${ }^{\mathrm{b}} p<0.01$ vs post-control value; ${ }^{\mathrm{c}} p<0.001$ vs post-control value

least significant difference test. The percentage change from control after each intervention was also compared with zero in the figure. For western blots, baseline expression was normalised to $100 \%$ and the post-intervention sample was expressed as a percentage change from the baseline expression. All data are presented as means \pm SEM, unless otherwise stated. All statistical analyses were performed using SPSS (Version 11.0, SPSS, Chicago, Ill., USA). All analyses were two-tailed and a $p$ value of 0.05 was deemed significant.

\section{Results}

Differences between baseline and post-intervention characteristics. There was no difference in baseline characteristics between the diet and exercise groups (Table 1). The apparent mean consumption of fat at baseline $(27 \%)$ was slightly below that estimated at the time of recruitment (30\%). Diet, but not exercise, was associated with a reduction in total energy consumption $(17 \pm 7 \%, p<0.05)$, including a reduction in consumption of saturated $(52 \pm 8 \%, p<0.001)$, monounsaturated $(41 \pm 10 \%, p<0.01)$ and polyunsaturated fats $(38 \pm 16 \%, p<0.05)$ (Table 3$)$. The percentage of energy derived from protein and carbohydrate consumption increased in the diet group but was unchanged by the exercise intervention. Cholesterol consumption and sodium excretion (hence estimated sodium consumption) were reduced by the dietary intervention $(29 \pm 12 \%$ and $25 \pm 10 \%$ respectively; $p<0.05$ for both). With the dietary intervention BMI was re- duced by $3.0 \pm 0.7 \%(p=0.01)$ and waist-to-hip ratio by $2.2 \pm 0.9 \%(p<0.05)$, while no changes were observed for the exercise intervention. Compliance with the exercise regimen was confirmed by an increase in $\mathrm{VO}_{2} \max (12 \pm 6 \%)$ and maximum work capacity $(16 \pm 6 \%)$ in the exercise but not the diet group $(p<0.05$ for both, Table 3 ).

Insulin and glucose. Fasting insulin was reduced by the dietary modification $(23 \pm 10 \%, p<0.05)$ and exercise training regimens $(19 \pm 8 \%, p<0.05)$ (Table 4$)$. Both interventions also reduced insulin secretion as assessed by the HOMA beta cell function parameter, but this was only significant for the diet group (Table 4). The HOMA insulin resistance index also tended to be reduced, although this was not statistically significant for either intervention ( $p=0.08$ for both). Fasting glucose levels were not significantly reduced by either intervention (Table 4 ).

Skeletal muscle TNF- $\alpha$ and GLUT4. There was a significant reduction in skeletal muscle TNF- $\alpha$ after the dietary intervention $(54 \pm 10 \%, p<0.05$, Fig. 1$)$, but no change with exercise training. The reduction in TNF- $\alpha$ with diet was independent of the small change in body weight $(-2.8 \pm 0.7 \mathrm{~kg}$; covariate analysis $p=0.94)$. Skeletal muscle GLUT4 protein levels were increased with exercise training $(105 \pm 37 \%, p<0.05)$ but were not altered with diet alone (Fig. 1). 
Table 4. Effects of dietary modification and exercise training on glucose and insulin

\begin{tabular}{|c|c|c|c|c|}
\hline & \multicolumn{2}{|l|}{ Diet group } & \multicolumn{2}{|c|}{ Exercise group } \\
\hline & Post control & Post diet & Post control & Post exercise \\
\hline Fasting glucose (mmol/l) & $5.72 \pm 0.32$ & $5.58 \pm 0.26$ & $5.67 \pm 0.28$ & $5.47 \pm 0.19$ \\
\hline Fasting insulin $(\mathrm{mU} / \mathrm{l})$ & $13.5 \pm 2.9$ & $9.0 \pm 1.4^{\mathrm{a}}$ & $14.0 \pm 2.1$ & $11.7 \pm 2.0^{\mathrm{a}}$ \\
\hline
\end{tabular}

HOMA, homeostasis model assessment, a $p<0.05$ vs post-control value
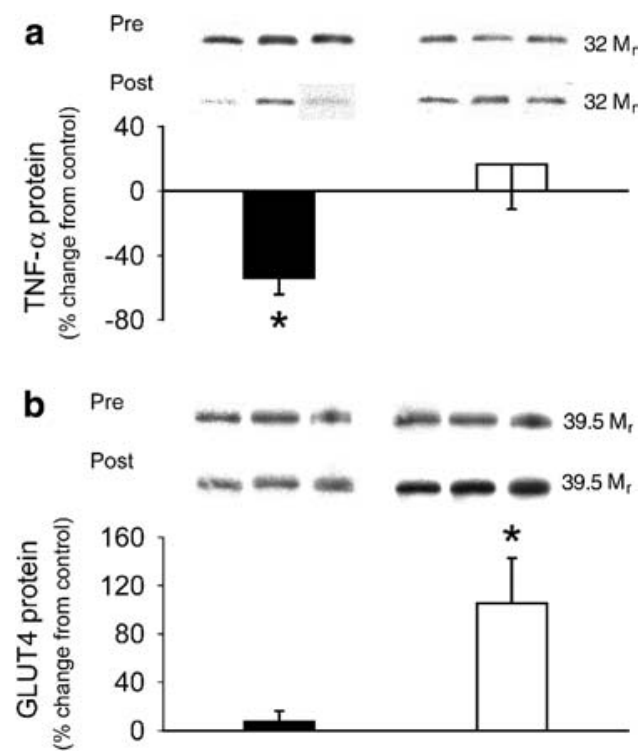

Fig. 1. Skeletal muscle TNF- $\alpha$ protein expression (a) and GLUT4 protein expression (b). Examples of three typical western blots are shown pre and post each intervention. Mean data are expressed as a percentage change from the post-control sample in the diet group (solid bars) and the exercise group (open bars). Data are means $\pm \mathrm{SEM}$; * represents a significant difference from post-control, $p<0.05$

Importantly there were no significant differences in any variables pre and post the control period.

\section{Discussion}

Glucose disposal occurs largely via skeletal muscle and may be modulated by TNF- $\alpha$ expression through effects on insulin receptor sensitivity and skeletal muscle GLUT4 protein level. Whether a reduction in skeletal muscle TNF- $\alpha$ is an important mechanism in the cardiovascular risk reduction associated with widely recommended diet and exercise interventions has not been studied to date. Our investigation suggests that a diet with a low glycaemic index, low in saturated fat, high in fibre, high in complex carbohydrates, and which is not specifically aimed at weight loss, reduces skeletal muscle TNF- $\alpha$ and may con- tribute to improved insulin sensitivity. This is probably due to improved insulin receptor sensitivity, rather than an effect on the GLUT4 glucose transporter, which was unchanged by the dietary intervention. In contrast to diet, skeletal muscle TNF- $\alpha$ levels were unchanged by moderate exercise training for 8 weeks. This suggests that the beneficial effects of exercise are not mediated via TNF- $\alpha$. As elevated blood levels of TNF- $\alpha$ are predictive of coronary heart disease and congestive heart failure [20], diet but not exercise may protect against the inflammatory consequences of elevated TNF- $\alpha$.

Dietary intervention. The dietary modification programme used in this study did not promote energy restriction. However, the total energy content of all food consumed over a 4-day period at the end of the 8 -week dietary intervention was reduced, although this resulted in only a modest reduction in BMI. Improvements in weight, BMI and waist-to-hip ratio are presumably due to this reduced energy intake. The consumption of a greater proportion of complex carbohydrates with a low glycaemic index may have reduced appetite and therefore total energy consumption [21]. With regard to fat consumption, the major response was a general reduction in total fat intake. Consumption of saturated, mono- and polyunsaturated fats was reduced, as was the ratio of saturated to polyunsaturated fat in the diet group, indicating good compliance with instructions for fat consumption. The reduction in 24-hour urinary sodium excretion also suggests that this group reduced sodium intake satisfactorily. Although dietary fibre intake was not significantly increased by dietary modification, the diet group nevertheless consumed the required fibre intake of more than 30 grams per day.

The dietary intervention used in the current study has been shown to effectively improve multiple cardiovascular risk factors including blood pressure, body weight, lipids and glucose metabolism [22, 23]. In particular, a higher ratio of carbohydrate to fat consumption has previously been associated with improved insulin sensitivity [24, 25, 26]. While fasting insulin levels in this study were reduced in conjunc- 
tion with the HOMA beta cell function index, the HOMA insulin resistance index just failed to reach statistical significance $(p=0.08)$. This may be related to the lack of substantial weight loss.

Our study also provides evidence that the observed improvements in glucose homeostasis are associated with reduced expression of skeletal muscle TNF- $\alpha$ protein. The likely mechanism involved is not related to effects on levels of GLUT4 expression, since this was unaffected by the dietary intervention. However, TNF- $\alpha$ inhibits the activity of the insulin receptor and some of its downstream effectors. Cell culture experiments have demonstrated that insulin-induced tyrosine phosphorylation of the $\beta$-subunit of the insulin receptor and IRS- 1 are reduced in the presence of TNF- $\alpha$ $[3,27]$. TNF- $\alpha$ promotes serine phosphorylation of IRS-1, which interferes with insulin-induced tyrosine phosphorylation and subsequent insulin signalling and action $[28,29]$. Data on the dietary intervention used in the current study are consistent with the amelioration of such inhibitory effects.

In a previous study skeletal muscle TNF- $\alpha$ mRNA levels and fasting plasma insulin were reduced after malabsorptive surgery causing substantial weight loss $(\sim 26 \mathrm{~kg})$ in severely obese women (BMI $\left.>40 \mathrm{~kg} / \mathrm{m}^{2}\right)$ [8]. In this previous study, GLUT4 mRNA levels were elevated, correlating inversely with the reduction in skeletal muscle TNF- $\alpha$ mRNA. In contrast to our study, it seems that TNF- $\alpha$ reduction with substantial weight loss may exert some of its effects through upregulation of GLUT4. In human and animal adipocyte cell cultures, TNF- $\alpha$ down-regulated GLUT4 transcription [2, 30, 31], while GLUT4 protein levels were correspondingly reduced [32]. Thus with severe weight loss [8], an increase in GLUT4 levels and increased insulin receptor sensitivity are likely to contribute to enhanced glucose metabolism. The same study also found that a low-energy diet inducing a weight reduction of $5 \mathrm{~kg}$ over 6 months did not influence insulin levels or skeletal muscle TNF- $\alpha$ mRNA levels, but compliance with the diet was poor [8]. In contrast to this previous study, which focused on energy restriction, the current data indicate that with a diet that is low in saturated fats, high in fibre and complex carbohydrates, and has a low glycaemic index, the reduction of skeletal muscle TNF- $\alpha$ may contribute to risk factor reduction.

Exercise intervention. The exercise group did not change their diet, but had higher $\mathrm{VO}_{2} \max$ and maximum workload after the 8-week exercise intervention, indicating compliance with the exercise regimen. Dietary parameter were unchanged by the exercise intervention. This exercise regimen has previously been associated with improvements in insulin sensitivity $[15,16]$, and strong trends consistent with such effects were observed $(p=0.08)$. In addition, fasting plasma insulin levels were significantly reduced.
While resistance training has been previously shown [14] to reduce skeletal muscle TNF- $\alpha$ mRNA and protein in the frail elderly, the current study is the first to our knowledge to examine an aerobic exercise regimen relevant to cardiovascular risk reduction. The broad age range in our study (33-59 years), in an obese group with elevated cardiovascular risk, makes our findings more relevant to cardiovascular disease prevention. Given the reduced fasting plasma insulin and unchanged skeletal muscle TNF- $\alpha$ protein levels in the exercise group, it is more likely that the $105 \%$ increase in skeletal muscle GLUT4 underlies the exercise-induced improvement in glucose metabolism. The relevant data are consistent with previous reports of increases in GLUT4 glucose transporter concentrations through aerobic exercise training $[33,34]$. The increase in GLUT4 transporters available to the plasma membrane of the cell may allow more efficient glucose uptake, an increase in insulin sensitivity and a consequent reduction in insulin levels [4].

The mean age of the participants in the study by Greiwe et al. [14] was 82 years and skeletal muscle TNF- $\alpha$ was higher in this group than in a young group (meanage 23 years). After 3 months of resistance training, skeletal muscle TNF- $\alpha$ decreased towards levels observed in the young group. The high initial TNF- $\alpha$ levels associated with ageing may have contributed to the positive effects of exercise in this case. Alternatively the mode of exercise (resistance vs aerobic) may account for the differences between the study of Greiwe et al. and the current report with regard to the effects of training.

Study limitations. The inclusion of an intervention that imparted dietary advice and recommendations precluded the use of a randomised longitudinal crossover study, as that advice could not be withdrawn once supplied. The invasive nature of the muscle biopsies also precluded a parallel control group in which the participants would not receive any dietary or exercise advice but would still have to submit to multiple biopsies. The 8-week control period was thus used as a time control and to correct for the effects of familiarisation.

Conclusion. A diet that has a low glycaemic index and is low in saturated fat, high in fibre and complex carbohydrate, and not specifically aimed at weight loss achieves at least some of its beneficial effects on glucose metabolism through a reduction in skeletal muscle TNF- $\alpha$ protein. Such effects may be mediated through improvements in insulin receptor sensitivity rather than an increase in skeletal muscle GLUT4. In contrast, moderate exercise training improves insulin sensitivity by increasing skeletal muscle GLUT4 levels, with TNF- $\alpha$ protein levels unchanged. Since TNF- $\alpha$ has been associated with impaired glucose metabolism and muscle wasting in the elderly [14], 
dietary intervention could be a simple way to avert the complications associated with metabolic disorders and reduced skeletal muscle mass.

\section{References}

1. Hofmann C, Lorenz K, Braithwaite SS et al. (1994) Altered gene expression for tumor necrosis factor-alpha and its receptors during drug and dietary modulation of insulin resistance. Endocrinology 134:264-270

2. Hotamisligil GS, Shargill NS, Spiegelman BM (1993) Adipose expression of tumor necrosis factor-alpha: direct role in obesity-linked insulin resistance. Science 259:87-91

3. Feinstein R, Kanety H, Papa MZ, Lunenfeld B, Karasik A (1993) Tumor necrosis factor-alpha suppresses insulininduced tyrosine phosphorylation of insulin receptor and its substrates. J Biol Chem 268:26055-26058

4. Kahn BB (1996) Lilly lecture 1995. Glucose transport: pivotal step in insulin action. Diabetes 45:1644-1654

5. Kern PA, Saghizadeh M, Ong JM, Bosch RJ, Deem R, Simsolo RB (1995) The expression of tumor necrosis factor in human adipose tissue. Regulation by obesity, weight loss, and relationship to lipoprotein lipase. J Clin Invest 95:2111-2119

6. Hotamisligil GS, Arner P, Caro JF, Atkinson RL, Spiegelman BM (1995) Increased adipose tissue expression of tumor necrosis factor-alpha in human obesity and insulin resistance. J Clin Invest 95:2409-2415

7. Saghizadeh M, Ong JM, Garvey WT, Henry RR, Kern PA (1996) The expression of TNF alpha by human muscle. Relationship to insulin resistance. J Clin Invest 97:11111116

8. Mingrone G, Rosa G, Di Rocco P et al. (2002) Skeletal muscle triglycerides lowering is associated with net improvement of insulin sensitivity, TNF-alpha reduction and GLUT4 expression enhancement. Int J Obes Relat Metab Disord 26:1165-1172

9. Pedersen BK, Bruunsgaard H, Ostrowski K et al. (2000) Cytokines in aging and exercise. Int $\mathrm{J}$ Sports Med 21:S4-S9

10. Ostrowski K, Rohde T, Asp S, Schjerling P, Pedersen BK (1999) Pro- and anti-inflammatory cytokine balance in strenuous exercise in humans. J Physiol 515:287-291

11. Horne L, Bell G, Fisher B, Warren S, Janowska-Wieczorek A (1997) Interaction between cortisol and tumour necrosis factor with concurrent resistance and endurance training. Clin J Sport Med 7:247-251

12. Tsukui S, Kanda T, Nara M, Nishino M, Kondo T, Kobayashi I (2000) Moderate-intensity regular exercise decreases serum tumor necrosis factor-alpha and HbA1c levels in healthy women. Int J Obes Relat Metab Disord 24:1207-1211

13. Nara M, Kanda T, Tsukui S et al. (1999) Running exercise increases tumor necrosis factor-alpha secreting from mesenteric fat in insulin-resistant rats. Life Sci 65:237244

14. Greiwe JS, Cheng B, Rubin DC, Yarasheski KE, Semenkovich CF (2001) Resistance exercise decreases skeletal muscle tumor necrosis factor alpha in frail elderly humans. FASEB J 15:475-482

15. Jennings G, Nelson L, Nestel P et al. (1986) The effects of changes in physical activity on major cardiovascular risk factors, hemodynamics, sympathetic function, and glucose utilization in man: a controlled study of four levels of activity. Circulation 73:30-40
16. Nelson L, Jennings GL, Esler MD, Korner PI (1986) Effect of changing levels of physical activity on blood pressure and haemodynamics in essential hypertension. Lancet 2:473-476

17. Balkau B, Charles MA (1999) Comment on the provisional report from the WHO consultation. European Group for the Study of Insulin Resistance (EGIR). Diabet Med 16:442443

18. Matthews DR, Hosker JP, Rudenski AS, Naylor BA, Treacher DF, Turner RC (1985) Homeostasis model assessment: insulin resistance and beta-cell function from fasting plasma glucose and insulin concentrations in man. Diabetologia 28:412-419

19. Haffner SM, Miettinen H, Stern MP (1997) The homeostasis model in the San Antonio Heart Study. Diabetes Care 20:1087-1092

20. Cesari M, Penninx BW, Newman AB et al. (2003) Inflammatory markers and onset of cardiovascular events: results from the Health ABC study. Circulation 108:23172322

21. Ludwig DS (2002) The glycemic index: physiological mechanisms relating to obesity, diabetes, and cardiovascular disease. JAMA 287:2414-2423

22. Appel LJ, Miller ER, Jee SH et al. (2000) Effect of dietary patterns on serum homocysteine: results of a randomized, controlled feeding study. Circulation 102:852-857

23. McCarron DA, Oparil S, Chait A et al. (1997) Nutritional management of cardiovascular risk factors. A randomized clinical trial. Arch Intern Med 157:169-177

24. Parker DR, Weiss ST, Troisi R, Cassano PA, Vokonas PS, Landsberg L (1993) Relationship of dietary saturated fatty acids and body habitus to serum insulin concentrations: the Normative Aging Study. Am J Clin Nutr 58:129136

25. Mayer-Davis EJ, Monaco JH, Hoen HM et al. (1997) Dietary fat and insulin sensitivity in a triethnic population: the role of obesity. The Insulin Resistance Atherosclerosis Study (IRAS). Am J Clin Nutr 65:79-87

26. Yang EJ, Kerver JM, Park YK, Kayitsinga J, Allison DB, Song WO (2003) Carbohydrate intake and biomarkers of glycemic control among US adults: the third National Health and Nutrition Examination Survey (NHANES III). Am J Clin Nutr 77:1426-1433

27. Hotamisligil GS, Murray DL, Choy LN, Spiegelman BM (1994) Tumor necrosis factor alpha inhibits signaling from the insulin receptor. Proc Natl Acad Sci USA 91:48544858

28. Kanety H, Feinstein R, Papa MZ, Hemi R, Karasik A (1995) Tumor necrosis factor alpha-induced phosphorylation of insulin receptor substrate-1 (IRS-1). Possible mechanism for suppression of insulin-stimulated tyrosine phosphorylation of IRS-1. J Biol Chem 270:2378023784

29. Hotamisligil GS, Peraldi P, Budavari A, Ellis R, White MF, Spiegelman BM (1996) IRS-1-mediated inhibition of insulin receptor tyrosine kinase activity in TNF-alphaand obesity-induced insulin resistance. Science 271:665668

30. Stephens JM, Pekala PH (1991) Transcriptional repression of the GLUT4 and C/EBP genes in 3T3-L1 adipocytes by tumor necrosis factor-alpha. J Biol Chem 266:2183921845

31. Hauner H, Petruschke T, Russ M, Rohrig K, Eckel J (1995) Effects of tumour necrosis factor alpha (TNF alpha) on glucose transport and lipid metabolism of newly differentiated human fat cells in cell culture. Diabetologia 38:764-771 
32. Stephens JM, Lee J, Pilch PF (1997) Tumor necrosis factoralpha-induced insulin resistance in 3T3-L1 adipocytes is accompanied by a loss of insulin receptor substrate- 1 and GLUT4 expression without a loss of insulin receptor-mediated signal transduction. J Biol Chem 272:971-976

33. Houmard JA, Shinebarger MH, Dolan PL et al. (1993) Exercise training increases GLUT-4 protein concentration in previously sedentary middle-aged men. Am J Physiol 264:E896-E901
34. Hughes VA, Fiatarone MA, Fielding RA et al. (1993) Exercise increases muscle GLUT-4 levels and insulin action in subjects with impaired glucose tolerance. Am J Physiol 264:E855-E862

35. The Expert Committee on the Diagnosis and Classification of Diabetes Mellitus (2003) Report of the expert committee on the diagnosis and classification of diabetes mellitus. Diabetes Care 26 [Suppl]:S5-S20 